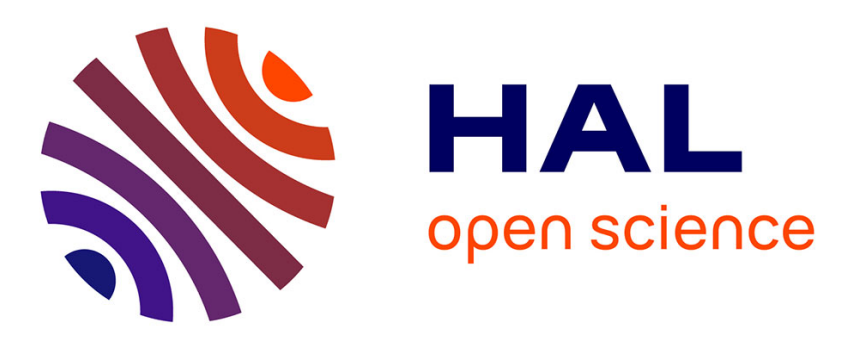

\title{
Effect of HP/T treatments of in-package food on additive migration from conventional and bio-sourced materials
}

Miguel Mauricio-Iglesias, Simon Jansana, Stéphane Peyron, Nathalie Gontard, Valérie Guillard

\section{To cite this version:}

Miguel Mauricio-Iglesias, Simon Jansana, Stéphane Peyron, Nathalie Gontard, Valérie Guillard. Effect of $\mathrm{HP} / \mathrm{T}$ treatments of in-package food on additive migration from conventional and bio-sourced materials. Food additives \& contaminants. Part A. Chemistry, analysis, control, exposure \& risk assessment, 2009, 27 (01), pp.118-127. 10.1080/19440040903268054 . hal-00572618

\section{HAL Id: hal-00572618 \\ https://hal.science/hal-00572618}

Submitted on 2 Mar 2011

HAL is a multi-disciplinary open access archive for the deposit and dissemination of scientific research documents, whether they are published or not. The documents may come from teaching and research institutions in France or abroad, or from public or private research centers.
L'archive ouverte pluridisciplinaire HAL, est destinée au dépôt et à la diffusion de documents scientifiques de niveau recherche, publiés ou non, émanant des établissements d'enseignement et de recherche français ou étrangers, des laboratoires publics ou privés. 


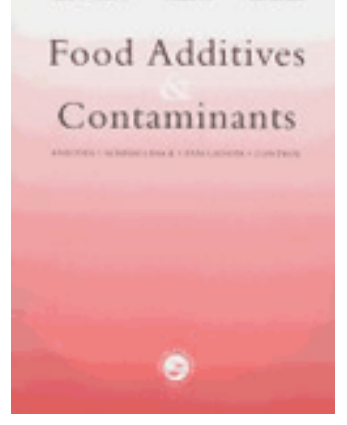

\section{Effect of HP/T treatments of in-package food on additive migration from conventional and bio-sourced materials}

\begin{tabular}{|r|l|}
\hline Journal: & Food Additives and Contaminants \\
\hline Manuscript ID: & TFAC-2009-191.R1 \\
\hline Manuscript Type: & Original Research Paper \\
\hline Author: & 17-Aug-2009 \\
\hline Complete List of Authors: & $\begin{array}{l}\text { Mauricio-Iglesias, Miguel; University Montpellier 2, UMR IATE } \\
\text { Jansana, Simon; University Montpellier 2, UMP IATE; University } \\
\text { Montpellier 2, UMR IATE } \\
\text { Peyron, Stéphane; University Montpellier 2, UMR IATE } \\
\text { Gontard, Nathalie; University Montpellier 2, UMR IATE } \\
\text { Guillard, Valérie; University Montpellier 2, UMR IATE }\end{array}$ \\
\hline Methods/Techniques: & Risk assessment \\
\hline Additives/Contaminants: & Packaging - food simulants, Packaging additives \\
\hline Food Types: & \\
\hline & \\
\hline
\end{tabular}

\section{SCHOLARONE Manuscripts}




\title{
Effect of high pressure/temperature (HP/T) treatments of in-package food on additive migration from conventional and bio-sourced materials
}

\author{
Mauricio-Iglesias, M. Jansana, S. Peyron, S. Gontard, N. Guillard, V. \\ UMR 1208 IATE (Agropolymer Engineering and Emerging Technology), University of Montpellier 2, \\ CIRAD, INRA, Montpellier Supagro \\ CC023, P1. E Bataillon F-34095 Montpellier FR
}


1 Abstract

2 Migration was assessed during and after two high pressure/temperature (HP/T) treatments intended to 3 perform a pasteurization (800 MPa for $5 \mathrm{~min}$, from 20 to $40^{\circ} \mathrm{C}$ ) and a sterilization treatment (800 $\mathrm{MPa}$

4 for $5 \mathrm{~min}$, from 90 to $115^{\circ} \mathrm{C}$ ) and were compared with conventional pasteurization and sterilization 5 respectively. The specific migration of actual packaging additives used as antioxidants and UV 6 absorbers (Irganox 1076, Uvitex OB) was investigated in a number of food-packaging system 7 combining one synthetic common packaging (LLDPE) and a bio-sourced one (PLA) in contact with 8 the four food simulating liquids defined by EC regulations. After standard HP/T processing, migration

9 kinetics was followed during the service life of the packaging material using FTIR spectroscopy. 10 LLDPE withstood the HP sterilization whereas it melted during the conventional sterilization. No 11 difference was observed on migration from LLDPE for both treatments. In the case of PLA, migration 12 of Uvitex OB was very low or not detectable for all the cases which were studied.

\section{Introduction}

15 In order to fulfill the increasing demand for high quality food, high pressure (HP) treatments stand as 16 one of the most promising new preservation technologies. Indeed, HP has been proven to be a mild 17 treatment able to render micro organisms inactive as well as the enzymes responsible for shelf-life 18 shortening with almost no modifications of the sensory and nutritional attributes of the product 19 (Rastogi et al. 2007) . In order to extend the applicability of HP, a number of papers have recently 20 appeared proposing the combination of pressure and temperature as a less aggressive method to 21 sterilize food than the conventional thermal sterilization (Ven et al. 2007; Wilson et al. 2008) . Since 22 food is packed before high pressure/thermal (HP/T) batch processing, the packaging material is also 23 exposed to non-conventional conditions of pressure and temperature. The packaging structure may be 
24 altered and consequently its mechanical and mass transfer (barrier and migration) properties as well 25 (Guillard et al. 2009) . Therefore, it is essential to assess properly the impact of this novel process on 26 migration in order to ensure its safety and avoid any potential health concern, especially since some 27 migration issues have recently raised public awareness on this subject (Anonymous 2005; Anonymous 28 2008).

Migration of a substance from packaging into food is a subject of growing interest for the scientific and legislative communities. Low and medium molecular weight substances, (e.g. plastic additives, 32 residual monomers) are not chemically bound to the polymer chains and can therefore migrate from 33 the polymer matrix, especially, when packaging undergoes severe conditions of temperature during 34 treatment. To date, research on mass transfer phenomena in packaging submitted to the couple effect of HP/T found that these treatments had no or slight effect on barrier properties of packaging materials e.g. Lopez-Rubio et al (2005) on gas permeation and conditions up to $800 \mathrm{MPa}$ and $75^{\circ} \mathrm{C}$; Schauwecker et al.(2002) on permeation of the pressure transmitting fluid (up to $827 \mathrm{MPa}$ and $75^{\circ} \mathrm{C}$ ); Caner et al(2004) and Kübel et al (1996) on aroma sorption (up to $800 \mathrm{MPa}$ and $60^{\circ} \mathrm{C}$ ). To our 39 knowledge, only one study (Caner and Harte 2005) was devoted to the impact of HP/T on specific migration of one additive (Irganox 1076 in PP) and did not observe any difference for treated samples at $800 \mathrm{MPa}$ and 40 or $60^{\circ} \mathrm{C}$.

The aim of this paper is to present a complete assessment of migration under pasteurization and 44 sterilization conditions. Therefore, it aims at extending the knowledge on migration including (i) the 45 four food simulating liquids (FSL) set by European Directive 85/572/EEC (1985); (ii) more severe 46 conditions of pressure/temperature coupled (up to $800 \mathrm{MPa}$ and $115^{\circ} \mathrm{C}$ ) and (iii) on new materials as 47 bio-sourced PLA. It is important to point out that even if olive oil is the fatty FSL set in priority by 
48 legislation, none of the previously cited studies has tested it, despite being the most aggressive FSL for 49 plastic materials. The conditions selected in this study were intended to represent sterilization and 50 pasteurization $\left(800 \mathrm{MPa} / 115^{\circ} \mathrm{C}\right.$ or $800 \mathrm{MPa} / 40^{\circ} \mathrm{C}$ respectively) in order to assess the migration of two 51 additives from one commercial synthetic polymer (LLDPE) and one commercial bio-sourced polymer 52 (PLA). In this purpose, the kinetics of mass transfer of the two model migrants from HP/T treated and 53 non-treated LLDPE and PLA in contact with the four recommended FSL was investigated. One of the 54 advantages of HP/T is the possibility to treat foodstuff in its final packaging and prevent the risk of 55 recontamination. With this scope, it seemed natural to assess not only the effect of the treatment itself 56 but also of the HP/T treatment and further storage. For evaluating migration a specific approach was 57 used based on the use of a non destructive method for mass transfer kinetic evaluation and a 58 mathematical model for identification of migrant diffusivity.

\section{Materials and Methods}

\section{Chemicals}

62 All surrogate compounds (Irganox 1076, Uvitex OB) and solvents were of reagent grade or highest 63 purity available. 2,5-Bis-(5-tert.-butyl-benzoxazol-2-yl)-thiophen (Uvitex OB, $430.6 \mathrm{~g} \mathrm{~mol}^{-1}$ ) was 64 purchased from Fluka. Octadecyl 3-(3,5-di-tertbutyl-4-hydroxyphenyl)propionate (Irganox 1076, 530 g $65 \mathrm{~mol}^{-1}$ ), was purchased from Sigma-Aldrich. Methanol (99.9\%), petroleum ether $\left(40-60^{\circ} \mathrm{C}\right.$, puriss), 66 tetrahydrofurane (THF, 98\%) and toluene (99\%) were purchased from Carlo Erba. Ethanol (99.8\% v) 67 and acetic acid (99-100\% v) were purchased from Riedel-de Haën. Olive oil was purchased in a local 68 supermarket. LLDPE pellets were purchased from Sigma Aldrich and PLA from Cargill Dow.

\section{Films fabrication}

70 LLDPE pellets were mixed with additives at $140^{\circ} \mathrm{C}(50 \mathrm{rpm})$ during $5 \mathrm{~min}$. PLA pellets were mixed with additives at $160^{\circ} \mathrm{C}(50 \mathrm{rpm})$ during $5 \mathrm{~min}$. The dough material obtained after mixing was then 
72 thermoformed (hot press) at 100 bars during $10 \mathrm{~min}$ at $140^{\circ} \mathrm{C}$ for LLDPE and $160^{\circ} \mathrm{C}$ for PLA. Films 73 preparation was kindly carried out by IMCB (Naples, Italy). Two additives were used as surrogate: 74 Irganox 1076 and Uvitex OB. Three different samples were studied: LLDPE + Irganox 1076, LLDPE $75+$ Uvitex OB and PLA + Uvitex OB, all at a nominal concentration of $0.4 \%$ w/w, higher than generally 76 recommended by the supplier (about $0.1 \% \mathrm{w} / \mathrm{w}$ ). Final film's thickness was $656 \pm 64 \mu \mathrm{m}$ for LLDPE $77+$ Uvitex OB, $492 \pm 25 \mu \mathrm{m}$ for LLDPE + Irganox 1076 and $274 \pm 48 \mu \mathrm{m}$ for PLA + Uvitex OB 78 measured by using a micrometer (Braive Instruments, Chécy, Fr).

\section{Sample treatments}

80 High pressure treatments. High pressure treatments were performed in a Resato hydrostatic pressure 81 apparatus in A\&F (Wageningen, Netherlands). For each case, the polymer strip was treated immersed 82 in the FSL. Immediately after the treatment, both were removed and put together in a glass flask, in 83 order to imitate the contact of an actual food product treated in its final packaging. Two different 84 treatments were applied:

85 - HP/HT treatment: $5 \mathrm{~min}$ at $800 \mathrm{MPa}$ and $115^{\circ} \mathrm{C}$ with a pressure build-up regime of $800 \mathrm{MPa} \mathrm{min}^{-1}$ 86 and a starting temperature of $90^{\circ} \mathrm{C}$ which rises to $115^{\circ} \mathrm{C}$ due to pressure; this treatment stands for a 87 high pressure sterilization.

88 - HP/LT treatment: $5 \mathrm{~min}$ at $800 \mathrm{MPa}$ and $40^{\circ} \mathrm{C}$ with a pressure build-up regime of $800 \mathrm{MPa} \mathrm{min}{ }^{-1}$ and 89 a starting temperature of $20^{\circ} \mathrm{C}$ which rises to $40^{\circ} \mathrm{C}$ due to pressure; this treatment stands for a high 90 pressure pasteurization.

91 Control. The treated samples were compared to an untreated control (UTC, $\left.40^{\circ} \mathrm{C}\right)$ that was immersed 92 in the FSL during 7 min in order to take into account the 5 min of treatment and time needed to build93 up and release the pressure ( 2 min overall). 
94 Conventional treatments. The high pressure treatments were also compared to classical equivalent 95 stabilization processes, i.e. thermal pasteurization and sterilization. The volume of FSL and surface of 96 films treated were identical to the other experiments. The conditions chosen were:

97 -Pasteurization: $30 \mathrm{~min}$ at $0.1 \mathrm{MPa}$ and $63^{\circ} \mathrm{C}$ in a stove.

98 -Sterilization: $20 \mathrm{~min}$ at $121^{\circ} \mathrm{C}$ in a Hydrolock ACB (Atelier de Technologie Alimentaire, Montpellier, 99 France).

100 9

\section{Migration kinetics}

Following the conditions set in directives 85/572/EEC (1985) and 2002/72/EC (2002), strips of polymers $\left(3.5 \mathrm{~cm}^{2}\right)$ were immersed in $6 \mathrm{~mL}$ of food simulating liquid, $\mathrm{FSL}$, and stored at $40^{\circ} \mathrm{C}$. Four FSL were used: distilled water, 3\% acetic acid, 15\% ethanol and olive oil. The time of exposition was extended from 10 to 26 days in order to obtain further information about the kinetic profile. The desorption of Uvitex OB and Irganox 1076 was determined in the film in triplicate using a nondestructive method (FTIR measurements) or a destructive method (extraction + UV). Before each measurement in FTIR, the strip of polymer is wiped, analyzed and then put again in the FSL. At the end of the migration test, the content of the remaining additive was determined in the polymer sample by using extraction + UV. The kinetics of Uvitex OB release from PLA was tentatively followed by FTIR (non-destructive method) but, unfortunately, high complexity of the PLA spectra prevented quantification of Uvitex OB concentration using this non-destructive method. As consequence, all results of Uvitex OB concentration in PLA are based on UV analysis of extracts. For each of the samples the concentration of additives was determined at 3, 6, 10, 15 and 26 days after the treatment by FTIR.

\section{FTIR measurements}


117 LLDPE film samples were analyzed by transmission FTIR. Spectra were recorded using a Nexus 5700 118 spectrometer (ThermoElectron Corp.) equipped with HeNe beam splitter and a cooled MCT detector. 119 Spectral data were accumulated from 128 scans with a resolution of $4 \mathrm{~cm}^{-1}$ in the range $800-4000 \mathrm{~cm}^{-1}$. 120 Three samples were employed for the measure and three spectra were recorded for each sample

All spectra pre-treatments were performed using Omnic v7.3 and TQ Analyst v7.3 softwares (ThermoElectron) Processing included: (1) a multipoint linear baseline correction, (2) a normalization according to the area of the LLDPE doublet $(1369-1378 \mathrm{~cm}-1)$ due to the $\mathrm{CH} 3$ symmetric deformation vibration.

The release of Uvitex OB from the sample was followed by the disappearance of a double bond aromatic peak at $1590 \mathrm{~cm}^{-1}$ A Partial Least Square (PLS) model was calibrated on the basis of the intensity ratio $1579 / 1378 \mathrm{~cm}^{-1}$. The regression produced a linear relationship $\left(\mathrm{R}^{2}=0.96, \mathrm{RMSE}=\right.$ $0.034 \% \mathrm{w} / \mathrm{w}$ ) between spectral data and additives concentration measured by UV analysis as explained afterwards.

Likewise, the release of Irganox 1076 from LLDPE samples was followed by the disappearance of the peak at $1235 \mathrm{~cm}^{-1}$ following a similar procedure. The PLS results for Irganox 1076 were $\mathrm{R}^{2}=0.97$, $\mathrm{RMSE}=0.019 \% \mathrm{w} / \mathrm{w}$.

FTIR measurements were successfully validated by measuring migration after 26 days of storage at $40^{\circ} \mathrm{C}$ using the UV method to determine the final content in the film.

\section{Raman spectroscopy}

Uvitex concentration profiles in the LLDPE were determined as follows. Thin slices of LLDPE were prepared using a razor blade and stuck on a microscope slide. Raman spectra were recorded between 
14195 and $3500 \mathrm{~cm}^{-1}$ Raman shift using a confocal Raman microspectrometer Almega (Thermo-Electron) 142 with the following configuration: excitation laser $\mathrm{He}-\mathrm{Ne} \lambda 0=633 \mathrm{~nm}$, grating 500 grooves $/ \mathrm{mm}$, 143 pinhole $25 \mu \mathrm{m}$, objective $\times 50$. The collection time was about $50 \mathrm{~s}$. Measurements were carried out in 144 the depth sample with a step size of $10 \mu \mathrm{m}$ from the sample center to the interface. All spectra pre2

\section{Solubility of Uvitex $O B$ in olive oil}

Uvitex OB solubility in olive oil was measured by a Varian Cary Eclipse Fluorimeter. The measurements of fluorescence intensity were done at two excitation wavelengths, 332 and $373 \mathrm{~nm}$, and detected at an emission wavelength of $434 \mathrm{~nm}$. The collection time was $1 \mathrm{~s}$. The results were averaged on the readings at the two excitations wavelengths.

Solutions of olive oil were oversaturated with Uvitex OB and kept for 20 days at $40^{\circ} \mathrm{C}$. A small volume of the supernatant was taken and diluted to 1:1000 or 1:2000 and then measured in the fluorimeter (in sextuplicate).

\section{Quantification of Uvitex $O B$ and Irganox 1076 using standard methods}

These standard methods were developed at the FP5 Foodmigrosure project (Anonymous 2004) .

Uvitex OB and Irganox 1076 were extracted from the polymers via dissolution in toluene at $103^{\circ} \mathrm{C}$ for

7 min for LLDPE and 5 min for PLA followed by a precipitation in methanol for LLDPE and in petroleum ether for PLA. The cooled solution was filtered to remove the precipitate and evaporated 
165 under vacuum at $50^{\circ} \mathrm{C}$ (for 7 min approximately). Calibration of the extraction procedure showed that 166 these conditions enabled stable and reproducible recovery $(88.5 \% \pm 0.6)$. The calibration and recovery 167 were determined following the same procedure as Nerin et al. (2003) . Dry extracts containing Uvitex OB were then dissolved in $10.0 \mathrm{ml}$ of THF and dry extracts containing Irganox 1076 were dissolved in $10.0 \mathrm{ml}$ methanol. The additive content was quantified by UV spectroscopy (Varian Cary 100 Scan, UV-Visible spectrophotometer) at $374 \mathrm{~nm}$ for Uvitex OB and $277 \mathrm{~nm}$ for Irganox 1076.

\section{Diffusivity identification}

173 In the case of a sheet of polymer immersed in a liquid of infinite volume and constant concentration, 174 the evolution of additive content with time is given by (Crank 1980) :

$$
\frac{C_{t}-C_{i n}}{C_{L, \infty}-C_{i n}}=1-\frac{8}{\pi^{2}} \sum_{n=0}^{\infty} \frac{1}{(2 n+1)^{2}} \exp \left[-\frac{(2 n+1)^{2} \pi^{2}}{L^{2}} D . t\right]
$$

where $C_{t}$ is average concentration in diffusing substance in the packaging at time $t, C_{i n}$ is the initial concentration in additive and $\mathrm{C}_{\mathrm{L}, \infty}$ is the concentration of the diffusing substance on the surface of the polymer required to maintain equilibrium with the concentration of this substance in the liquid at any time t.

Additive diffusivity was identified from experimental data by minimizing the root mean square error (RMSE) between experimental and predicted data (Equation 1) using an optimization method (Levenberg-Marquardt algorithm predefined in Matlab (Mathworks, USA) software). A Monte Carlo sampling was applied to the input parameters (concentration, thickness and time) in order to determine the $95 \%$ confidence intervals of the determined diffusivity as detailed elsewhere (Hessler 1997; Press et al. 1989) . 


\section{Results and Discussion}

189 Uvitex OB is an optical brightener and UV stabilizer approved for use in food contact material (FCM) 190 with a specific migration limit (SML) of $0.6 \mathrm{mg} \mathrm{kg}^{-1}(2002 / 72 / \mathrm{EEC})$. Irganox is an antioxidant approved for FCM with a specific migration limit (SML) of $6 \mathrm{mg} \mathrm{kg}^{-1}$ (2002/72/EEC).

These two molecules were selected to spike the studied samples (LLDPE and PLA) because of (i) their excellent thermal stability (for example, according to the supplier datasheet, the thermogravimetrical analysis on Uvitex $\mathrm{OB}$ shows a loss of only $1 \%$ weight at $280^{\circ} \mathrm{C}$ ) (ii) their relatively high diffusivities in polymers allowing to easily observe migration kinetics in LLDPE (Dole et al. 2006; Helmroth et al. 2002) and (iii) their easy detection and quantification using both standard methods (HPLC, UV) and spectroscopic method such as FTIR and Raman (Mauricio-Iglesias et al. 2009). The objective was to assess the influence of HP/T treatments comparing:

- $\quad$ HP sterilization-like treatment $\left(800 \mathrm{MPa}, 115^{\circ} \mathrm{C}, 5 \mathrm{~min}\right)$

- $\quad$ HP pasteurization like treatment $\left(800 \mathrm{MPa}, 40^{\circ} \mathrm{C}, 5 \mathrm{~min}\right)$

- $\quad$ Conventional sterilization $\left(20 \mathrm{~min}\right.$ at $\left.121^{\circ} \mathrm{C}\right)$ in autoclave

- $\quad$ Conventional mild pasteurization $\left(30 \mathrm{~min}\right.$ at $\left.63^{\circ} \mathrm{C}\right)$

- Untreated control (abbreviated to UTC, $40^{\circ} \mathrm{C}, 7 \mathrm{~min}$ to take into account the time of build-up and release of pressure, approx 2 min)

\section{Determination of Uvitex $\mathrm{OB}$ solubility in olive oil}

Before tackling the assessment of migration of additives it was essential to gather some information about its solubility. A rather low upper bound for the solubilities in water of both Irganox 1076 and Uvitex OB can be found in the safety data sheet, however there is no indication of their solubility in olive oil. Irganox 1076 is consistently more soluble in non polar solvents than in polar ones, what 
212 allows considering its solubility in olive oil as very high (probably of the same order of magnitude as 213 in n-hexane, $320 \mathrm{~g} \mathrm{~kg}^{-1}$ ). For Uvitex OB, a quite complex molecule, it is not easy to find a trend (a 214 solubility scale could be built as chloroform $>$ ethyl acetate $>$ acetone $>n$-hexane $>$ methanol). Therefore, 215 the solubility was obtained experimentally giving a result of $5 \pm 2 \mathrm{~g} \mathrm{~L}^{-1}$ of Uvitex in olive oil.

\section{LLDPE treatment and migration tests}

Migration experiments were performed on untreated control (UTC) and treated samples (HP/HT, HP/LT and conventional pasteurization and sterilization) of LLDPE spiked with Uvitex OB (initial quantity of $0.41 \pm 0.10 \% \mathrm{w} / \mathrm{w}$ ) or Irganox 1076 (initial quantity of $0.37 \pm 0.023 \% \mathrm{w} / \mathrm{w}$. The kinetic release of Uvitex OB and Irganox 1076 was monitored with FTIR measurements that supplied the content of Uvitex or Irganox in the polymer strip. Concerning the thermal sterilization treatment, none of the migration results could be obtained since the sterilized samples melted during the sterilization process, which indeed made them useless for packaging purposes. This was not surprising since the melting point of the LLDPE used had been determined near $115^{\circ} \mathrm{C}$. However, it should be emphasized that the LLDPE samples, which underwent the HP at high temperature (HP/HT, sterilization-like treatment) kept their integrity in turn. This result underpinned the fact that if a packaging material cannot withstand a thermal treatment; an equivalent treatment might be done with high pressure.

The migration of Irganox 1076 during the HP/T treatment alone (no further storage), was assessed by comparing the quantity of remaining additive before and after the treatment (Figure 1A). As it can be seen, migration is much higher in olive oil than in the aqueous FSL (in almost all cases lower actually than the limit of quantification for the FTIR method estimated at $0.03 \% \mathrm{w} / \mathrm{w}$ in the film). Indeed, 234 Irganox 1076 is much more soluble in hydrophobic solvents such as olive oil than in polar aqueous 
235 solvents; Irganox 1076 solubility in $\mathrm{n}$-hexane is equal to $320 \mathrm{~g} \mathrm{~kg}^{-1}$ of solution compared to less than $2360.3 \mathrm{~g} \mathrm{~kg}^{-1}$ in water (Sanches Silva et al. 2006).

According to Figure 1, no effect of HP/T treatment was observed on Irganox 1076 migration from LLDPE into FSL after HP/T treatment and subsequent storage compared to the control. This result was in accordance with that obtained by Caner and Harte (2005) for PP after HP treatment (800 MPa) and 20 days of storage at 40 and $60^{\circ} \mathrm{C}$ : no significant differences in the migration level of Irganox 1076 were observed by these authors after HP treatment into the tested FSL (95\% and 10\% ethanol) compared to the controls. Regarding temperature, which is a known activating factor of migration, when the release after the treatment and 10 days of storage is considered, the losses in pasteurized samples appear as significantly higher $(\mathrm{p}=0.05)$ than the untreated control (UTC) but this result was not confirmed after storage. A question to be answered is if this higher release is caused during the treatment or if the treatment modifies the polymer in a way that the release during storage is enhanced. Unfortunately, the high deviation of the results after treatment (as the concentration becomes steadily lower) hinders the potential conclusions about temperature (losses in pasteurization are only higher than those after HP/LT and UTC for a p-value of 0.2).

Likewise, the migration of Uvitex $\mathrm{OB}$ during the HP/T treatment alone (no further storage), was assessed by comparing the quantity of remaining additive before and after the treatment (Figure 2A). For both HP/T treatments and the UTC, the release of the initial content of Uvitex OB was of around $10 \%$ in aqueous FSL and $15 \%$ in olive oil. Concerning conventional pasteurization, the pasteurized samples gave similar results to the UTC and HP treated samples whereas significantly higher losses were found in olive oil. In short, HP treatments represented an advantage as i) the LLDPE samples studied could withstand HP sterilization but not the conventional treatment and ii) migration of 
259 pasteurized samples was higher in olive oil and not significantly different in the rest, compared to the 260 UTC or the HP samples.

The quantity of remaining Uvitex OB in the HP/T treated LLDPE and the non treated ones was compared after 10 days and 26 days of storage in the same FSL in which they were treated. The resulting losses in Uvitex $\mathrm{OB}$ are reported after 10 days (Figure 2B) and 26 days (Figure 2C) migration.

The losses of Uvitex $\mathrm{OB}$ after 10 days storage at $40^{\circ} \mathrm{C}$ ranged from 35 to $53 \%$ in water, acetic acid and ethanol FSL and as expected, reached higher losses (from 73 to $77 \%$ ) in olive oil. The solubility of Uvitex $\mathrm{OB}$ in olive oil has been estimated in this study as $5 \pm 2 \mathrm{~g} \mathrm{~L}^{-1}$ of olive oil. On the contrary, solubility in water and aqueous simulants is hardly measurable $\left(<0.3 \mathrm{~g} \mathrm{~L}^{-1}\right.$ of water according to the supplier data sheet). After 26 days storage at $40^{\circ} \mathrm{C}$, losses of Uvitex OB in LLDPE ranged from 57 to $70 \%$ in water, acetic acid and ethanol FSL and almost $90 \%$ in olive oil what confirmed the conclusions already drawn at 10 days of storage.

Concerning the HP/T treatment, no significant effect of HP treatment was observed after HP/T treatment and 10 or 26 days of storage, either with the control or the pasteurized samples. Effectively, the significant differences detected between the pasteurized samples and the others (Figure 2A) became no longer noticeable after the time of storage, suggesting that the importance of the storage step is higher than that of the treatment itself, either HP or conventional.

Taking into account the low solubility of Uvitex OB in aqueous FSL, unexpected high losses of Uvitex OB from LLDPE into FSL were observed (Figures 2A, B \& C) even for aqueous simulants in which 
283 Uvitex OB solubility is very low $\left(<0.03 \mathrm{~g} \mathrm{~L}^{-1}\right.$ in water which is likely close to solubility in $3 \%$ acetic 284 acid and $15 \%$ ethanol). A mass balance was made to check the results between the losses in the films

and the migrates in the FSL. However, the quantity of Uvitex OB released could not be found back dissolved in the aqueous FSL. The examination of the tissue sheets used to wipe the polymer strips before the FTIR analysis showed traces of Uvitex OB powder. As an illustration, the amount released by the samples in water for the UTC would represent a concentration of $0.5 \mathrm{~g} \mathrm{~kg}^{-1} \mathrm{FSL}$, more than ten folds higher than the already overestimated value of solubility $\left(<0.03 \mathrm{~g} \mathrm{~kg}^{-1}\right)$. Actually, Uvitex OB turned out to be stuck to the surface of the polymer film, where it had previously emerged. This phenomenon characterized by a loss of additive from the bulk of the polymer that emerges or "blooms" on the surface is called blooming (sometimes also referred to as bleeding). In principle, blooming occurs when the additive concentration is higher than its solubility in the polymer (Billingham 2001) although it has been observed that supersaturated metastable solutions were possible (Spatafore and Pearson 1991). Blooming is well known in industry and sometimes difficult to avoid as the quantities of additive needed to be effective may be higher than the solubility in the polymer. Raman microspectroscopy analysis has confirmed blooming of Uvitex OB in LLDPE (Figure 3 and Figure 4) showing an accumulation of additive nearby the interface of the film. In this case study, blooming could have been intensified for the high concentrations of additive used. In any case, an important conclusion arises from the precedent discussion; blooming is a realistic phenomenon that may occur (although infrequently) in real packaging and must be taken into account in migration tests.

According to control points made after 26 days of storage in the polymers and the FSL using the standard method, the mass balance regarding what remained in the polymer strip and what migrated into the FSL was incomplete confirming that a partial quantity of Uvitex OB had been taken off during the migration test by wiping. This phenomenon can lead to migration artifacts and highlights the 
307 importance of checking the mass balance between the film and the FSL. It can be noticed that 308 migration tests based only on quantifying the amount of additive in the FSL would not have detected it 309 whereas it can be critical in some cases i.e. when packaging solid foodstuff that can mechanically wipe 310 the "bloomed" additive or if the additive sticks to the surface of the foodstuff.

\section{PLA treatment and migration tests}

The same tests (UTC, HP/HT, HP/LT, thermal pasteurization and thermal sterilization) were carried out on PLA spiked with Uvitex OB (initial concentration of $0.52 \pm 0.04 \% \mathrm{w} / \mathrm{w}$ based on UV analysis of extracts as stated previously). It is important to point out that PLA withstood the sterilization process, whether thermal or HP/HT since it has a melting point, $\mathrm{T}_{\mathrm{m}}$, at about $175^{\circ} \mathrm{C}$ whereas $\mathrm{LLDPE} \mathrm{T}_{\mathrm{m}}$ lies between $\left.100-120^{\circ} \mathrm{C}\right)$. However, the appearance of PLA underwent unequivocal changes after both sterilization treatments. PLA became whitish, translucent and brittle which made it unsuitable for packaging applications. Indeed PLA is heated above its glass transition temperature $\left(\mathrm{T}_{\mathrm{g}} \sim 60^{\circ} \mathrm{C}\right)$ for sterilization processes, whether it be thermal sterilization or high pressure sterilization (even if the $\mathrm{T}_{g}$ of PLA is not known at $800 \mathrm{MPa}$, the HP treatment requires the sample to be at $90^{\circ} \mathrm{C}$ before the pressure build-up, and thus, above the $\mathrm{T}_{\mathrm{g}}$ ). This transition may promote tempering and recrystallization of PLA, therefore changing its structure and modifying its appearance. If this crystallization also occurs during the HP treatment is not easy to know. Indeed, $\mathrm{T}_{\mathrm{g}}$ increases with pressure first linearly and then asymptotically but the value of $\mathrm{T}_{\mathrm{g}}$ at $800 \mathrm{MPa}$ is not known to date (Iannace and Mensitieri, Personal communication) .

For all the treatments and FSL and even after 26 days of storage, release of Uvitex OB from PLA was so slow that the differences in concentration with initial concentration lay within the error of the quantification method (estimated in $0.03 \% \mathrm{w} / \mathrm{w}$ ). PLA appears thus as a good barrier material 
331 concerning migration of a medium molecular weight additive, and, to the accuracy of this study, its 332 performance was not modified by high pressure treatments. It is not known however if the structural 333 modifications undergone at high temperature could however enhance the migration of smaller 334 molecules than Uvitex OB $\left(431 \mathrm{~g} \mathrm{~mol}^{-1}\right)$ and it should be studied in further detail.

\section{Determination of mass transfer parameters}

Mass transfer from packaging to foodstuff can be well simulated provided that three parameters are known, diffusivity in the polymer (D), the partition coefficient polymer/foodstuff (KPL) and the mass transfer coefficient $(\mathrm{k})$, although the latter can be ignored in many practical cases as its influence is low compared to the diffusivity in the material (Pocas et al. 2008). Roughly the KPL represents the values of migration at equilibrium and $\mathrm{D}$, how fast equilibrium is reached. The use of this parameter makes easier the comparison of results inter-studies since it allows to get rid of the influence of variable experimental set-ups (e.g. polymer thickness, polymer/FSL mass ratio). With the scope of fully characterizing this case study, the mass transfer parameters were determined when possible. Otherwise, at least a rough estimation is provided whenever the results prevented an accurate determination of the parameters. The mathematical model used to determine the diffusivity consisted on Fick's law (Equation 1) and the assumption that the FSL surrounding the sample was close to zero. The diffusivity values obtained are not the "actual" diffusivities but for the UTC, since in the other cases the kinetics includes not only the storage but also the treatment (HP/LT and HP/HT). According to Figures 1 and 2, this influence would be negligible. Anyway, these values are suitable for the comparison of the whole migration story of the packaging/FSL system. Figure 5 shows an example of model fitting for HP/HT treated samples. 
354 On the other hand, the phenomena assessed here are more complex in the case of Uvitex OB in 355 LLDPE because of blooming of the additive. To the best of our knowledge, little has been published 356 on the kinetics of blooming. Spatafore and Pearson (1991) found that the kinetics of blooming of

Uvitex OB diffusivity in LLDPE was determined for each FSL and for treated or non treated polymers using the kinetic profile obtained by FTIR. The diffusivity values found for Uvitex OB (Table 1) were in good accordance with those found in the literature: $3.2 \times 10^{-14} \mathrm{~m}^{2} \mathrm{~s}^{-1}$ (measured with Moisan cells) and $5 \times 10^{-14} \mathrm{~m}^{2} \mathrm{~s}^{-1}$ (measured with sorption kinetics) in LLDPE (Dole et al. 2006). Besides the root mean square error (RMSE) was in all the cases of the same order of magnitude of the experimental error. For the same FSL, no significant difference was found between the HP/T treated samples and the control although clear differences were detected between different FSL. Likewise, diffusivity values are in agreement with the migration tests showing that there is no significant difference within FSL for each of the treatments but, that the release is faster in olive oil. Olive oil is widely regarded as a plasticizer of plastics that could increase diffusion and then. However, a number of authors have found that olive oil did not have a significant influence on migration of medium weight molecules from polyolefins (Helmroth et al. 2002; Mauricio-Iglesias et al. 2009; O'Brien et al. 1999) Therefore, the discrepancy of diffusivity in olive oil and the other FSL can be linked likely to the inaccuracy of the assumption that Equation (1) correctly describes the blooming phenomena. 
378 The diffusivity of Irganox 1076 in LLDPE was only determined in olive oil (Table 2) since the release 379 in the aqueous FSL was too low to be measured. In any case, the results of diffusivity confirm the data 380 shown previously (Figure 1) and no significant effect of HP/T is reflected in the values obtained. 381

Since no difference of concentration could be measured in the case of PLA, the diffusivity values of Uvitex OB could not be determined either. However, the maximum experimental error, which provides consequently the maximum difference in concentration, can be used to roughly estimate an upper bound for the value of diffusivity. This maximum experimental error was evaluated as $0.08 \%$ w/w, i.e. the distance between the two bound of the confidence interval of Uvitex OB concentration in PLA. An upper estimation of diffusivity was then determined as if $0.08 \% \mathrm{w} / \mathrm{w}$ had been released to any of the FSL after 26 days of storage. Thus, taking into account the common criterion of considering the partition coefficient polymer/foodstuff $(\mathrm{KPL})$ as $\mathrm{KPL}=1000$ if the additive is not soluble in the FSL and KPL = 1 otherwise (Practical Guide, 2003), two diffusivity values were estimated, one for aqueous FSL and another for olive oil. Using these values in equation 1 gave an estimation of $4 \times 10^{-15}$ $\mathrm{m}^{2} \mathrm{~s}^{-1}$ for the maximum diffusivity of Uvitex OB in aqueous FSL and $5 \times 10^{-17} \mathrm{~m}^{2} \mathrm{~s}^{-1}$ for olive oil. These two values show how, even considering a worst case as a KPL $=1000$, the diffusivity in PLA is much lower than in LLDPE.

\section{Conclusion}

According to migration test results no effect of HP/T treatments and HP/T treatments +26 days of storage on Uvitex OB and Irganox 1076 migration from LLDPE into four standard FSL was observed. Furthermore, when the HP/T treated samples were compared to an equivalent stabilization process, i.e. thermal pasteurization and sterilization, the advantages were clear. The LLDPE samples did not withstand the thermal sterilization process whereas no change on migration and/or appearance was 
401 detected for HP/HT sterilization. For pasteurized samples, there were no differences between 402 conventional pasteurized and HP/LT treated samples.

\section{Acknowledgments}

Authors would like to acknowledge Prof. Salvatore Iannace and co-workers from IMCB (Naples, Italy) for the preparation of the packaging samples used in this study and the analysis of their thermal properties. This study has been carried out with financial support from the Commission of the European Communities, Framework 6, Priority 5 'Food Quality and Safety', Integrated Project NovelQ FP6-CT-2006-015710.

\section{References}

Anonymous 2004. Determination of 2-hydroxy-4-(octyloxy)benzophenone (c81) and 2,5-bis(5-tertbutyl-2-benzoxazolyl)thiophene (UOB) in high density polyethylene (HDPE) and polypropylene (PP) in FP5 Foodmigrosure QLK1-CT20022390.http://www.ivv.fraunhofer.de/no_html/16_81_UOB_CP.PDF

Anonymous 2005. ITX - Isopropyl Thioxanthone in IDFA-Infant and dietetic foods association.http://www.idfa.org.uk/news_full.aspx?id=79\&cat=4 
424 Anonymous 2008. Bisphenol A in food packaging in Sense about 425 Science.http://www.senseaboutscience.org.uk/index.php/site/other/141

Billingham, N. C. The Physical Behaviour of Polymer Additives. 2001 Plastic Additives Handbook Munich Hanser H. Zweifel, Ed.; Chapter The Physical Behaviour of Polymer Additives. pp 1017-1046.

Caner, C.; Hernandez, R. J.; Pascall, M.; Balasubramaniam, V. M.; Harte, B. R. 2004. The effect of high-pressure food processing on the sorption behaviour of selected packaging materials. Packaging Technology and Science 17, 139-153.

Caner, C.; Harte, B. 2005. Effect of high-pressure processing on the migration of antioxidant Irganox 1076 from polypropylene film into a food simulant. Journal of the Science of Food and Agriculture 85, 39-46.

Crank, J. 1980. The Mathematics of Diffusion, 1st ed.; USA, Oxford University Press.

Dole, P.; Feigenbaum, A. E.; De la Cruz, C.; Pastorelli, S.; Paseiro, P.; Hankemeier, T.; Voulzatis, Y.; Aucejo, S.; Saillard, P.; Papaspyrides, C. 2006. Typical diffusion behaviour in packaging polymers - application to functional barriers. Food Additives and Contaminants 23, 202-211.

European 1985. 85/572/EEC Council Directive of 19 December 1985 laying down the list of simulants to be used for testing migration of constituents of plastic materials and articles intended to come into contact with foodstuffs.

European 2002. 2002/72/EC Commission Directive of 6 August 2002 relating to plastic materials and articles intended to come into contact with foodstuffs.

European 2003. A Practical Guide for Users of European Directives, Unit "Chemical and physical risks; surveillance" of the Health \& Consumer Protection Directorate-General of the European Commission, 
447 Guillard, V.; Mauricio-Iglesias, M.; Gontard, N. 2009. Effect of novel food processing methods on 448 packaging: structure, composition and migration properties. Critical Reviews in Food Science

Helmroth, I. E.; Dekker, M.; Hankemeier, T. 2002. Influence of solvent absorption on the migration of Irganox 1076 from LDPE. Food Additives and Contaminants 19, 176-183.

Hessler, J. P. 1997. The use of Monte Carlo simulations to evaluate kinetic data and analytic approximations. International Journal of Chemical Kinetics 29, 803-817.

Iannace, S.; Mensitieri, G. Personal Communication.

Kuebel, J.; Ludwig, H.; Marx, H.; Tauscher, B. 1996. Diffusion of aroma compounds into packaging films under high pressure. Packaging Technology and Science 9, 143-152.

Lopez-Rubio, A.; Lagaron, J. M.; Hernandez-Munoz, P.; Almenar, E.; Catala, R.; Gavara, R.; Pascall, M. A. 2005. Effect of high pressure treatments on the properties of EVOH-based food packaging materials. Innovative Food Science \& Emerging Technologies 6, 51-58.

Mauricio-Iglesias, M.; Peyron, S.; Guillard, V.; Gontard, N. 2009. Application of FTIR and Raman microspectroscopy to the study of food/packaging interactions. Food Additives and Contaminants (submitted).

Nerin, C.; Fernandez, C.; Domeno, C.; Salafranca, J. 2003. Determination of Potential Migrants in Polycarbonate Containers Used for Microwave Ovens by High-Performance Liquid Chromatography with Ultraviolet and Fluorescence Detection. Journal of Agricultural and Food Chemistry 51, 5647-5653

O'Brien, A.; Goodson, A.; Cooper, I. 1999. Polymer additive migration to foods - a direct comparison of experimental data and values calculated from migration models for high density polyethylene (HDPE). Food Additives and Contaminants 16, 367-380. 
470 Pocas, M. F.; Oliveira, J. C.; Oliveira, F. A. R.; Hogg, T. 2008. A Critical Survey of Predictive 471 Mathematical Models for Migration from Packaging. Critical Reviews in Food Science and $472 \quad$ Nutrition 48, 913-928.

Press, W. H.; Flannery, B. P.; Teukolsky, S. A.; Vetterling, W. T. Numerical Recipes in Pascal. 1989 Cambridge University Press; Chapter Numerical Recipes in Pascal. pp 547-599.

Rastogi, N. K.; Raghavarao, K.; Balasubramaniam, V. M.; Niranjan, K.; Knorr, D. 2007. Opportunities and challenges in high pressure processing of foods. Critical Reviews in Food Science and Nutrition 47, 69-112.

Sanches Silva, A.; Sendon Garcia, R.; Cooper, I.; Franz, R.; Paseiro Losada, P. 2006. Compilation of analytical methods and guidelines for the determination of selected model migrants from plastic packaging. Trends in Food Science \& Technology 17, 535-546.

Schauwecker, A.; Balasubramaniam, V. M.; Sadler, G.; Pascall, M. A.; Adhikari, C. 2002. Influence of high-pressure processing on selected polymeric materials and on the migration of a pressuretransmitting fluid. Packaging Technology and Science 15, 255-262.

Spatafore, R.; Pearson, L. T. 1991. Migration and Blooming of Stabilizing Antioxidants in Polypropylene. Polymer Engineering and Science 31, 1610-1617.

Ven, C. v. d.; Courvoisier, C.; Matser, A. 2007. High pressure versus heat treatments for pasteurisation and sterilisation of model emulsions. Innovative Food Science \& Emerging Technologies 8, 230-236.

Wilson, D. R.; Dabrowski, L.; Stringer, S.; Moezelaar, R.; Brocklehurst, T. F. 2008. High pressure in combination with elevated temperature as a method for the sterilisation of food. Trends in Food Science \& Technology 19, 289-299. 


\section{Figure captions.}

Figure 1. Comparison of Irganox 1076 losses from LLDPE in contact with four different FSL after high pressure $(800 \mathrm{MPa}, 5 \mathrm{~min})$ at low temperature $\left(\mathrm{LT}, 20-40^{\circ} \mathrm{C}\right)$ and high temperature (HT, 90$\left.115^{\circ} \mathrm{C}\right)$ with conventional pasteurisation $\left(63^{\circ} \mathrm{C}, 30 \mathrm{~min}\right)$ and untreated control (UTC, $\left.40^{\circ} \mathrm{C}, 7 \mathrm{~min}\right)$ after treatment (A); or treatment and storage at $40^{\circ} \mathrm{C}$ for 10 days (B) or 26 days (C).

Figure 2. Comparison of Uvitex OB losses from LLDPE in contact with four different FSL after high pressure $(800 \mathrm{MPa}, 5 \mathrm{~min})$ at low temperature $\left(\mathrm{LT}, 20-40^{\circ} \mathrm{C}\right)$ and high temperature $\left(\mathrm{HT}, 90-115^{\circ} \mathrm{C}\right)$ with conventional pasteurisation $\left(63^{\circ} \mathrm{C}, 30 \mathrm{~min}\right)$ and untreated control $\left(\mathrm{UTC}, 40^{\circ} \mathrm{C}, 7 \mathrm{~min}\right)$ after treatment (A); or treatment and storage at $40^{\circ} \mathrm{C}$ for 10 days (B) or 26 days (C).

Figure 3: Raman spectra at different depths of LDPE film

Figure 4: Initial concentration profile of Uvitex OB in the depth of LLDPE samples according to Raman measurements

Figure 5: Examples of Uvitex OB migration kinetic from HP/HT treated LDPE into FSL at $40^{\circ} \mathrm{C}$ measured by non-destructive FTIR method (symbols, $\square$ water, $\mathbf{\Delta} 3 \%$ acetic acid, $\circ 15 \%$ ethanol, olive oil , experimental data; solid lines, model fitting) 

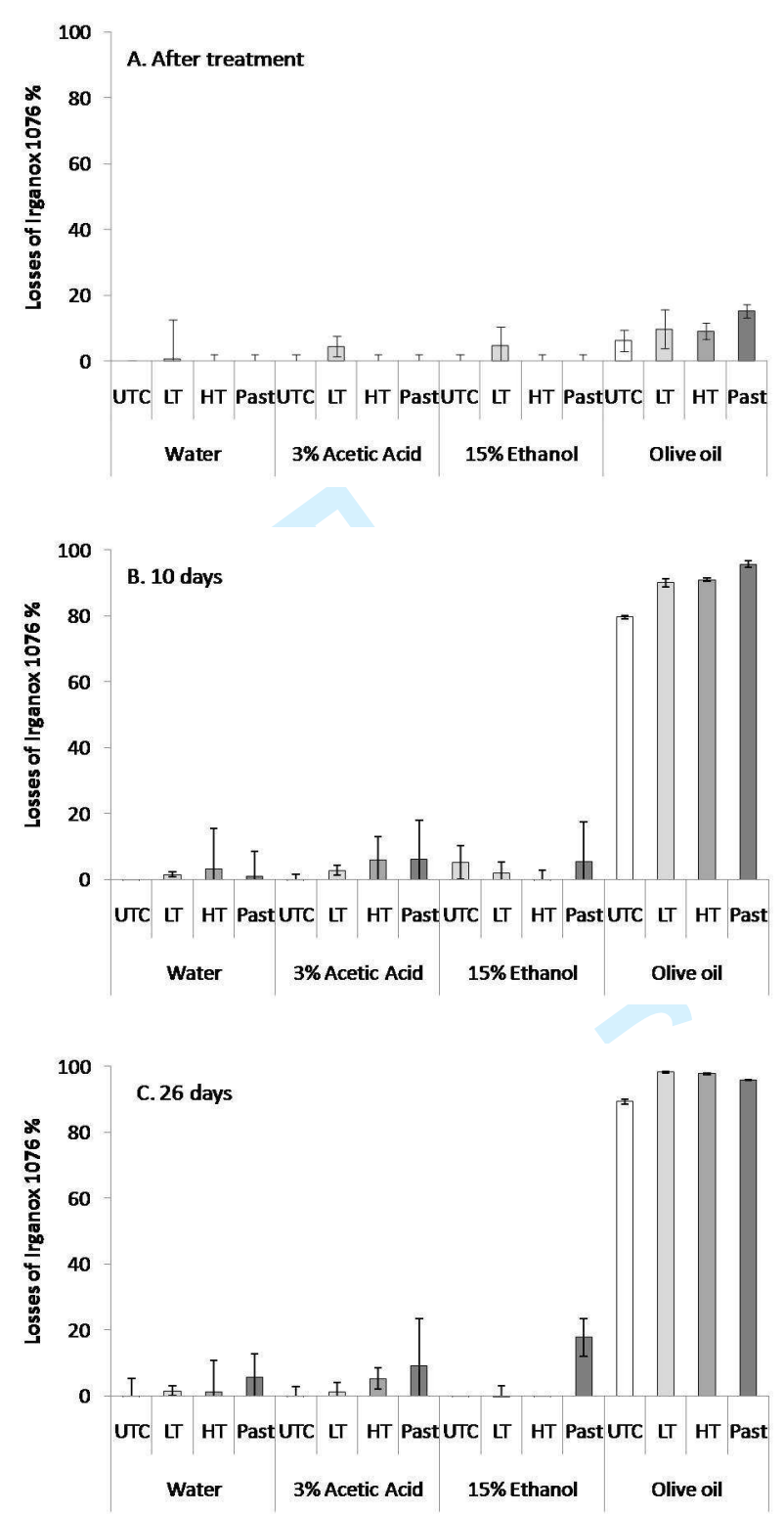

Figure 1. Comparison of Irganox 1076 losses from LLDPE in contact with four different FSL after high pressure (800 $\mathrm{MPa}, 5 \mathrm{~min})$ at low temperature (LT, 20-40 $\left.{ }^{\circ} \mathrm{C}\right)$ and high temperature (HT, 90$\left.115^{\circ} \mathrm{C}\right)$ with conventional pasteurisation $\left(63^{\circ} \mathrm{C}, 30 \mathrm{~min}\right)$ and untreated control (UTC, $\left.40^{\circ} \mathrm{C}, 7 \mathrm{~min}\right)$ after treatment (A); or treatment and storage at $40^{\circ} \mathrm{C}$ for 10 days (B) or 26 days (C). 

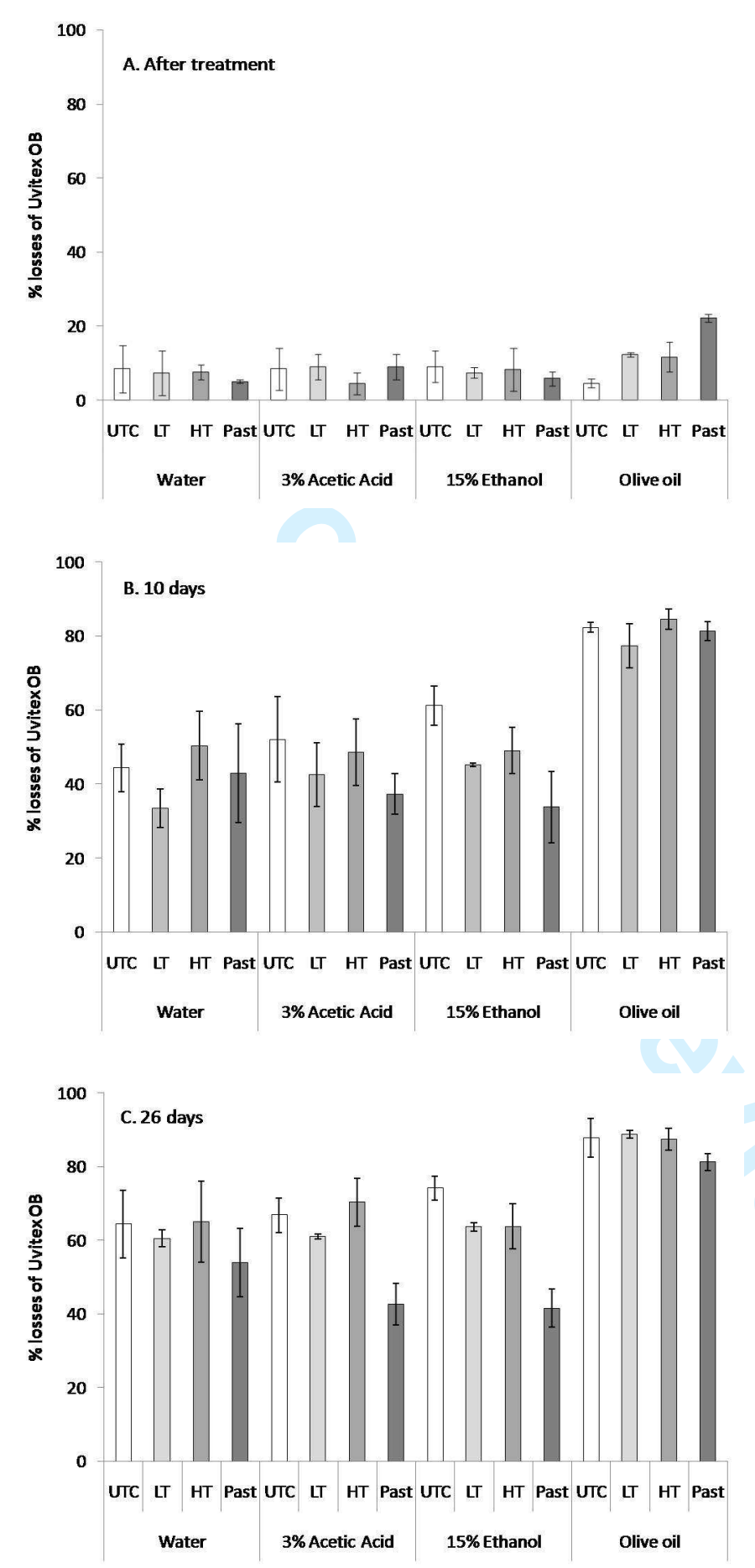

Figure 2. Comparison of Uvitex OB losses from LLDPE in contact with four different FSL after high pressure $(800 \mathrm{MPa}, 5 \mathrm{~min})$ at low temperature $\left(\mathrm{LT}, 20-40^{\circ} \mathrm{C}\right)$ and high temperature $\left(\mathrm{HT}, 90-115^{\circ} \mathrm{C}\right)$ with conventional pasteurisation $\left(63^{\circ} \mathrm{C}, 30 \mathrm{~min}\right)$ and untreated control $\left(\mathrm{UTC}, 40^{\circ} \mathrm{C}, 7 \mathrm{~min}\right)$ after treatment (A); or treatment and storage at $40^{\circ} \mathrm{C}$ for 10 days (B) or 26 days (C). 


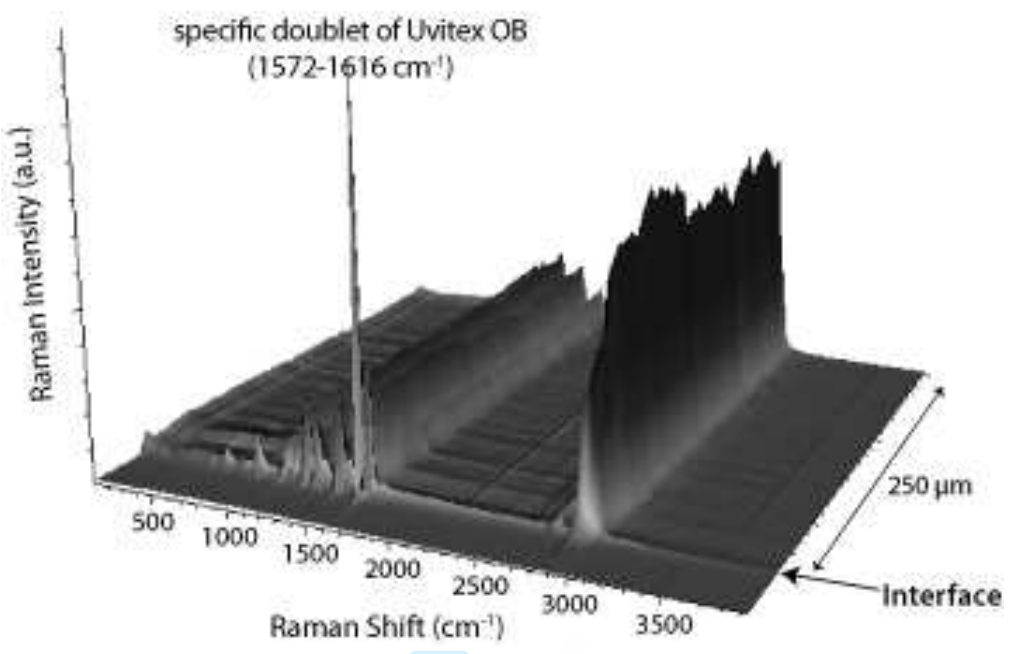

Figure 3: Raman spectra at different depths of LDPE film 


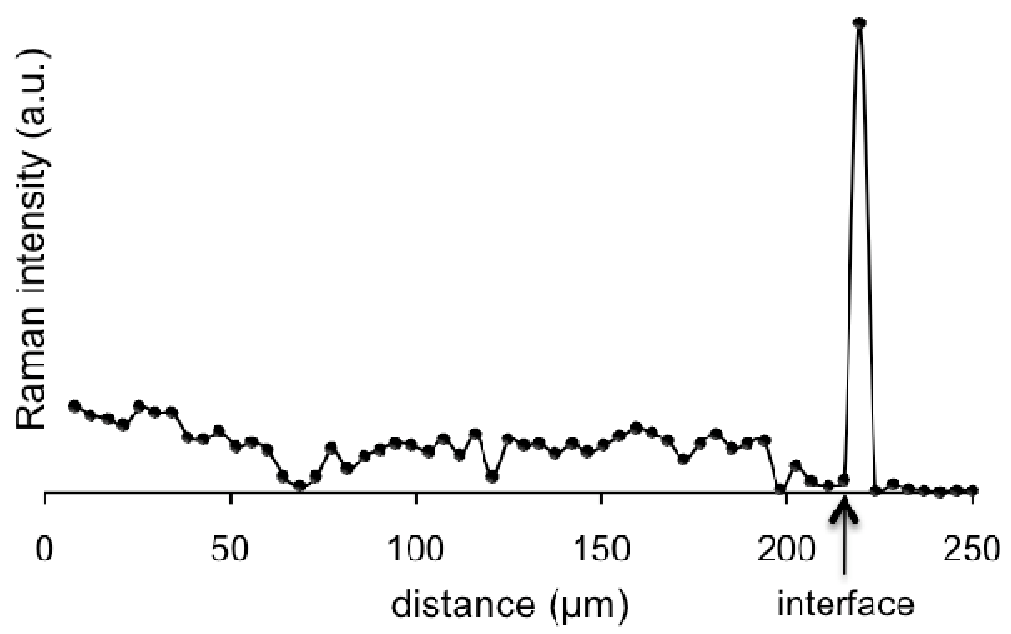

Figure 4: Initial concentration profile of Uvitex OB in the depth of LLDPE samples according to Raman measurements 


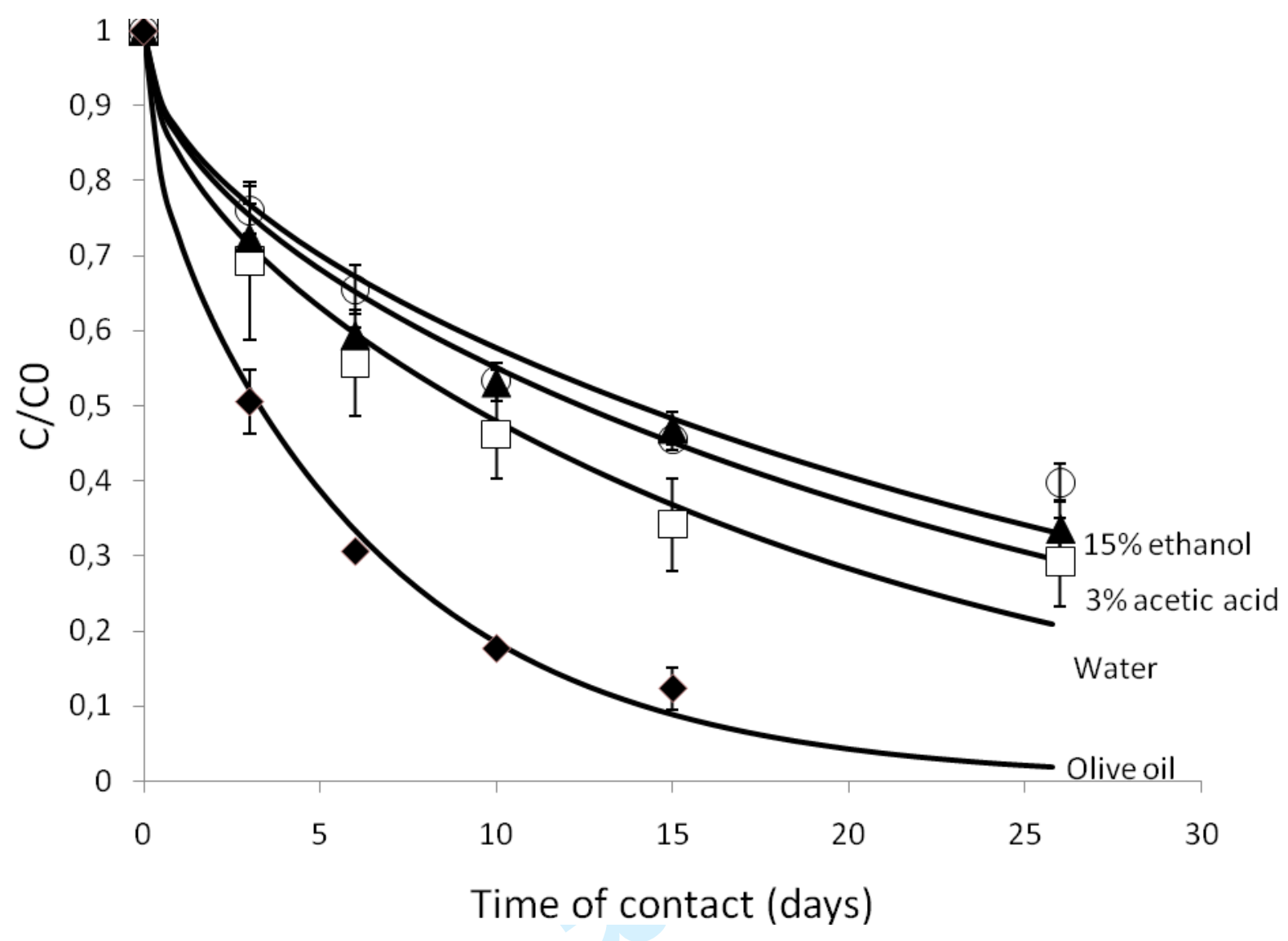

Figure 5: Examples of Uvitex OB migration kinetic from HP/HT treated LDPE into FSL at $40^{\circ} \mathrm{C}$ measured by non-destructive FTIR method (symbols, $\square$ water, $\mathbf{\Delta} 3 \%$ acetic acid, $\circ 15 \%$ ethanol, $\bullet$ olive oil , experimental data; solid lines, model fitting) 
Table 1. Diffusivity of Uvitex OB in the system LLDPE/simulant after HP/T and 26 days of storage at $40^{\circ} \mathrm{C}$

\begin{tabular}{lllll}
\hline Diffusivity $\left(10^{-14}\right) \mathrm{m}^{2} \mathrm{~s}^{-1}$ & Water & $3 \%$ Acetic Acid & $15 \%$ Ethanol & Olive Oil \\
\hline UTC & $1.8 \pm 0.4^{\mathrm{a}, \mathrm{b}}$ & $2.3 \pm 0.5^{\mathrm{b}}$ & $3.1 \pm 0.7^{\mathrm{b}}$ & $8.2 \pm 1.7^{\mathrm{c}}$ \\
HP/LT $\left(20-40^{\circ} \mathrm{C}\right)$ & $1.4 \pm 0.3^{\mathrm{a}, \mathrm{b}}$ & $1.8 \pm 0.5^{\mathrm{a}, \mathrm{b}}$ & $2.1 \pm 0.4^{\mathrm{b}}$ & $6.2 \pm 1.3^{\mathrm{c}}$ \\
HP/HT $\left(90-115^{\circ} \mathrm{C}\right)$ & $2.3 \pm 0.5^{\mathrm{b}}$ & $2.1 \pm 0.4^{\mathrm{b}}$ & $2.2 \pm 0.4^{\mathrm{b}}$ & $8.3 \pm 1.6^{\mathrm{c}}$ \\
Pasteurization $\left(63^{\circ} \mathrm{C}\right)$ & $1.1 \pm 0.3^{\mathrm{a}}$ & n.d. & n.d. & $8.2 \pm 1.6^{\mathrm{c}}$
\end{tabular}

Means with different letters are significantly different $(\mathrm{p}<0.05)$ 
Table 2. Diffusivity of Irganox 1076 in the system LLDPE/olive oil after HP/T and 26 days of storage at $40^{\circ} \mathrm{C}$

\begin{tabular}{lc}
\hline & Diffusivity $\left(10^{-14}\right) \mathrm{m}^{2} \mathrm{~s}^{-1}$ \\
\hline UTC & $4.6 \pm 0.9$ \\
HP/LT $\left(20-40^{\circ} \mathrm{C}\right)$ & $3.7 \pm 0.7$ \\
HP/HT $\left(90-115^{\circ} \mathrm{C}\right)$ & $4.4 \pm 0.9$ \\
Pasteurization $\left(63^{\circ} \mathrm{C}\right)$ & $5.5 \pm 1.2$ \\
\hline
\end{tabular}

